\title{
The Role of Solvent in Tautomer Solvate Crystallization: A Case of 6-Amino-1,3-Dimethyl-5-Nitrosouracil
}

\author{
Luguang $\mathrm{Qi}^{1} \cdot$ Yanhui Jin ${ }^{2} \cdot$ Huina $\mathrm{Li}^{1} \cdot$ Yanpeng Dong ${ }^{1} \cdot$ Chuang Xie ${ }^{1,3}$
}

Received: 18 January 2020 / Revised: 16 February 2020 / Accepted: 21 February 2020 / Published online: 13 April 2020

(c) The Author(s) 2020

\begin{abstract}
Tautomers are structural isomers that readily interconvert and may exhibit different properties. The effect of solvent on tautomeric equilibria in solution has been a subject of some research. Tautomer solvate is less common, and the role of solvent in the crystallization of tautomer solvate remains an interesting topic. In this work, we used 6-amino-1,3-dimethyl5-nitrosouracil (NAU) as the tautomeric model material, which can present in nitrone-enamine form (Tautomer A) or oxime-imine form (Tautomer B). A solvate with NAU/DMSO ratio of 1:1 was discovered and characterized using single/ powder X-ray diffraction and thermogravimetry. The crystal structure of NAU.DMSO was determined for the first time, where only Tautomer A was formed in the tautomeric crystal. Quantum chemical calculation and molecular dynamics simulation were conducted to determine the tautomeric form in DMSO solution. Electrostatic potential analysis, radial distribution function analysis, and binding energy suggested possible DMSO-NAU interaction modes and stable tautomer complexes in solution. Tautomer A-containing complexes were found to dominate in solution, as verified by comparing predicted and experimental ${ }^{1} \mathrm{H}$ NMR spectra. Findings reveal that the hydrogen bonding between DMSO and NAU is similar in solution and in NAU-DMSO solvate crystal, which helps preserve the form of Tautomer A during solvate crystallization.
\end{abstract}

Keywords Tautomerization $\cdot$ Solvate $\cdot$ Molecular dynamics simulation $\cdot$ Quantum chemical calculation

\section{Introduction}

Tautomerism describes the isomers of a compound with uncertainty of proton position [1]. Around $10 \%$ of the molecules in the Cambridge Structural Database (CSD) have the potential for tautomerism [2]. Tautomerism is complex, and the tautomeric compounds have two to dozens of tautomers; for example, warfarin can exist in 40 distinct tautomeric forms [3]. Tautomers may have very different physical

Electronic supplementary material The online version of this article (https://doi.org/10.1007/s12209-020-00247-7) contains supplementary material, which is available to authorized users.

Chuang Xie

acxie@tju.edu.cn

1 School of Chemical Engineering and Technology, Tianjin University, Tianjin 300072, China

2 Xinhua Pharmaceutical (Shouguang) Co., Ltd, Weifang 262700, China

3 National Collaborative Innovation Centre of Chemical Science and Engineering (Tianjin), Tianjin 300072, China chemical properties, such as optical properties [4], absorption in Raman spectra [5], and bioactivities [6], thereby making tautomerism an interesting and useful topic.

An equilibrium exists between different tautomeric forms in solution, which can be influenced by the nature of solvent, $\mathrm{pH}$, and solvent temperature [2,7]. Many efforts have been made on the tautomerization in solution [8-14]. The interconversion of tautomers in crystals is concerned with tautomeric polymorphism [15], which can be changed by illumination and temperature change $[16,17]$. According to Cruz-Cabeza and Groom [2], multiple tautomers can be observed in 37 crystal structures of the CSD, which means more than one tautomer exist in these crystal structures.

Varieties of crystal engineering methods have been used to achieve tautomeric polymorphisms, such as cocrystallization, salinization, and solvation. Wang et al. [1] prepared 11 new solid forms, including salts, cocrystals, and ionic cocrystals. Wang et al. [18] obtained a cocrystal containing both keto and enol tautomers of acesulfame. Joseph et al. [19] found that 5-hydroxynicotinic acid can exist in a zwitterionic tautomer conformation in hydrate but in a nonionic tautomer conformation in DMSO solvate. The introduction 
of solvent in crystal is an easy way to obtain tautomeric polymorphisms by forming solvate. For tautomeric solvate, the solvent effect on tautomerization in solution and in crystal may vary due to different arrangements and the local environments, which are seldom studied. Joseph et al. [19] studied tautomeric form preservation during crystallization. However, a comprehensive understanding remains absent on how the solvent molecules influence the tautomeric forms in solution and eventually in crystal.

6-Amino-1,3-dimethyl-5-nitrosouracil (NAU) is an intermediate of $\mathrm{N}$-oxide organic photoredox catalysts [20] and caffeine [21]. A pair of NAU tautomeric forms (Fig. 1) has been reported $[22,23]$. Tautomer A has amino and nitroso groups, while Tautomer B has imino and oximido groups, of which the fundamental difference is the position of $\mathrm{H} 1$ (or $\left.\mathrm{H} 1^{\prime}\right)$. In this paper, we choose NAU and DMSO to analyze the role of solvent in the crystallization of tautomer. We first discovered the DMSO solvate of NAU and determined the tautomeric form in crystal. Then, the possible tautomeric forms in DMSO solution were studied in detail through experiments and theoretic computation, including molecular dynamics simulation and quantum chemical calculation. Furthermore, we compared the interactions between NAU and DMSO molecules in solution and crystal to discuss the role of solvent in the crystallization of solvate.

\section{Experimental}

\section{Materials}

NAU $\cdot \mathrm{H}_{2} \mathrm{O}$ (99.5\% purity, CCDC number: 1198925$)$ was purchased from Xinhua Pharmaceutical (Shouguang) Co., Ltd., China. NAU was obtained from the dehydration of $\mathrm{NAU} \cdot \mathrm{H}_{2} \mathrm{O}$. DMSO (99.5\% purity) was purchased from Lianlong Bohua (Tianjin) Pharmaceutical Chemistry Co., Ltd., China. DMSO-d6 (99.9\% purity) was purchased from Kmart (Tianjin) Chemical Technology Co., Ltd., China.

\section{Preparation of DMSO Solvate of NAU}

Anhydrous NAU was prepared by drying NAU $\cdot \mathrm{H}_{2} \mathrm{O}$ in a vacuum oven at $120{ }^{\circ} \mathrm{C}$ for $2 \mathrm{~h}$. The as-prepared anhydrous NAU (about $300 \mathrm{mg}$ ) was dissolved in $5 \mathrm{~mL} \mathrm{DMSO}$ at $50{ }^{\circ} \mathrm{C}$ for $3 \mathrm{~h}$ in a 10-mL screw-capped vial. The solution was filtered by an organic membrane $(0.45 \mu \mathrm{m})$ and transferred into another screw-capped vial. Then, the vial was allowed to naturally cool to room temperature. Good-quality crystals that are suitable for single-crystal X-ray diffraction (SCXRD) can be obtained in $12 \mathrm{~h}$.

\section{Characterizations}

\section{Power X-Ray Diffraction}

The samples were all analyzed by power X-ray diffraction (PXRD) using a D/MAX 2500 diffractometer $(\mathrm{Cu}-\mathrm{K} \alpha$ radiation $1.5406 \AA$ ) at $40 \mathrm{kV}$ and $100 \mathrm{~mA}$. The scanning range was from $2^{\circ}$ to $50^{\circ}$ at a step of $8^{\circ} / \mathrm{min}$. The collected data were analyzed by using commercial software Jade (version $6.0)$.

\section{Thermogravimetry}

Thermogravimetry (TG) analysis [24] was carried out on a Mettler Toledo TGA/DSC 1/SF. Samples (about 5-10 mg) were placed in a $70 \mu \mathrm{L}$ standard alumina pan and heated from 30 to $300{ }^{\circ} \mathrm{C}$ at a heating rate of $10{ }^{\circ} \mathrm{C} / \mathrm{min}$ under a nitrogen flow of $20 \mathrm{~mL} / \mathrm{min}$.

\section{Single-Crystal X-Ray Diffraction}

SCXRD data were collected on a Rigaku XtaLAB P200 diffractometer using graphite-monochromatized Mo Ko radiation $(\lambda=0.71073 \AA)$. The structure was solved using SHELXS-97 [25] and refined using SHELXL-97 [26].

Fig. 1 Tautomers of NAU
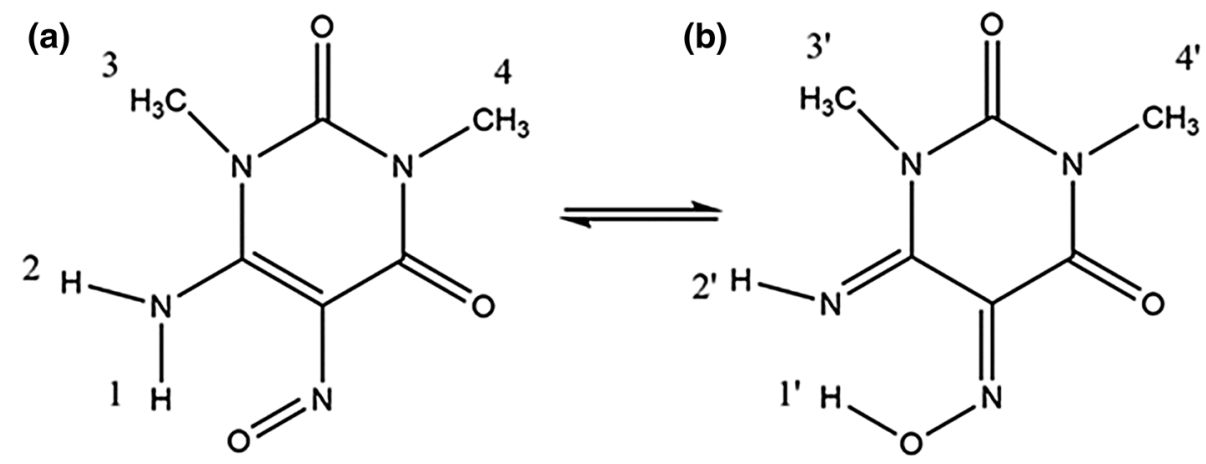


\section{${ }^{1} \mathrm{H}$ Nuclear Magnetic Resonance Spectra}

${ }^{1} \mathrm{H}$ nuclear magnetic resonance spectra $\left({ }^{1} \mathrm{H}\right.$ NMR) experiment was performed at $500 \mathrm{MHz}$ on a Varian INOVA spectrometer equipped with a positive phase probe. About $10 \mathrm{mg}$ NAU was dissolved in $5 \mathrm{~mL}$ DMSO-d $\mathrm{d}_{6}$. Data were analyzed by MestReNova (version 6.1).

\section{Molecular Dynamics Simulation}

To evaluate the interaction between NAU and DMSO, radial distribution function (RDF) analysis was performed using molecular dynamics (MD) simulation in Materials Studio (version 17.1). The structures of NAU tautomers and DMSO were first generated manually. These structures were then used to build amorphous cells with periodic boundary conditions. The quantities of Tautomer A or B and DMSO were decided according to the concentration of solution in the ${ }^{1} \mathrm{H}$ NMR experiment. Two dynamics experiments were conducted. One amorphous cell contained 8 Tautomer A and 1000 DMSO (8A-1000DMSO), and the other amorphous cell contained 8 Tautomer B and 1000 DMSO (8B-1000DMSO). The amorphous cells were subjected to geometry and dynamics simulation using Dreiding force field [27]. In dynamics simulation, an NVT (fixed number of particles, volume, and temperature) ensemble method was selected at a temperature of $298.15 \mathrm{~K}$. The time step was $1.0 \mathrm{fs}$ with a total simulation time of $500 \mathrm{ps}$, controlled by Andersen thermostat [28]. Then, the RDF was computed using the $\mathrm{O}$ atom of DMSO and the $\mathrm{N}$ atom of $-\mathrm{NH}_{2}$ from Tautomer A or the $\mathrm{N}$ atom of $=\mathrm{NH}$ from Tautomer $\mathrm{B}$. Finally, some hydrogen bonding complexes were obtained by setting the angle of $\mathrm{X}-\mathrm{H}-\mathrm{A}$ not less than $90^{\circ}$ and the distance of H-A not more than $3.0 \AA$ [29] in Materials Studio. DMSO molecules that have a van der Waals interaction with NAU as indicated by dynamics simulation results are eliminated to simplify the calculations.

\section{Quantum Chemical Calculation}

The geometries of NAU tautomers, hydrogen bonding complexes, and transition state were optimized at the B97D/6$31+\mathrm{G}(\mathrm{d}, \mathrm{p})[30]$ level in vacuum or DMSO solvent using IEFPCM models [31] in GAUSSIAN 09. Hydrogen bonding complexes were generated from molecule dynamics experiments. To calculate the transition state (TS), we used the Berny method [32] in GAUSSIAN 09. To correct dispersion, the keyword "em $=\mathrm{gd} 3$ " was used in all calculations [33]. Single-point energies were calculated for the optimized ground states and TS $[2,33]$ at the B97D/def2QZVPP level [30], in which the method was the same as the optimization calculation, but the basis was larger. The binding energy between NAU and DMSO in each complex is calculated by the following formula:

$\Delta E_{\text {binding }}=E_{\text {complex }}-\left(E_{\mathrm{NAU}}+n E_{\mathrm{DMSO}}\right)$

where $E_{\text {complex }}$ is the energy of each complex; $E_{\mathrm{NAU}}$ is the energy of Tautomer A or B (determined by the NAU tautomer form in each complex); $n$ is the number of DMSO in each complex; and $E_{\mathrm{DMSO}}$ is the energy of DMSO molecule. ${ }^{1} \mathrm{H}$ NMR chemical shifts $(\delta)$ were calculated relative to those of tetramethylsilane (TMS) by using the gauge-including atomic orbital (GIAO) method [30, 34]. The ${ }^{1} \mathrm{H}$ NMR data for optimized structures and TMS were calculated at B97D/6-31+ G(d,p) [30] and B3LYP/6-311+G(d,p) [35], respectively, in GAUSSIAN 09.

Molecular electrostatic potential (ESP) analysis was performed at B97D/def2QZVPP, which was the same as the level used in single-point energy analysis. ESP was projected onto the van der Waals surface. Multiwfn and visual molecular dynamics (VMD) were used for ESP analysis [36, 37].

\section{Results and Discussion}

\section{DMSO Solvate of NAU and Tautomer in Its Crystal}

The PXRD pattern of the crystals obtained from DMSO solution was compared with that of anhydrous NAU and NAU. $\mathrm{H}_{2} \mathrm{O}$ in Fig. 2. The crystals obtained from DMSO have distinct characteristic peaks at $2 \theta=7.69^{\circ}, 9.09^{\circ}, 15.07^{\circ}$, and $22.85^{\circ}$, which are different from the characteristic peaks of either NAU $\cdot \mathrm{H}_{2} \mathrm{O}\left(12.44^{\circ}, 16.46^{\circ}, 17.00^{\circ}\right.$, and $\left.18.68^{\circ}\right)$ or NAU $\left(9.34^{\circ}, 12.38^{\circ}, 13.96^{\circ}\right.$, and $\left.14.76^{\circ}\right)$. This finding reveals that the crystal obtained from DMSO is a new crystalline phase of NAU.

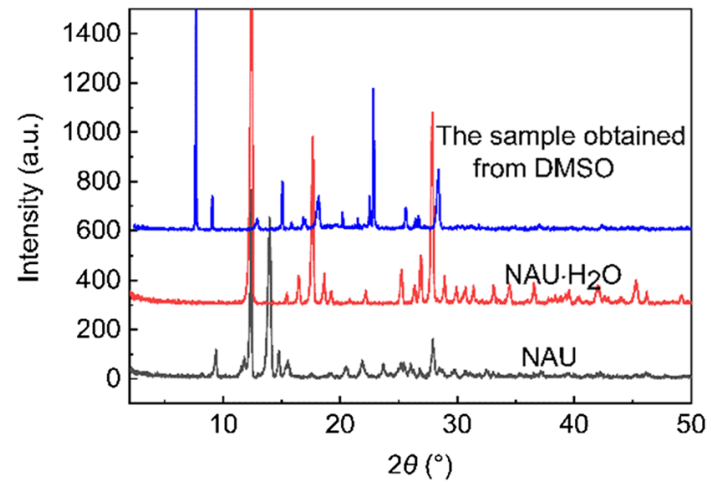

Fig. 2 PXRD patterns of NAU, NAU $\cdot \mathrm{H}_{2} \mathrm{O}$, and the sample obtained from DMSO 
The new phases of NAU and the sample obtained from DMSO were then analyzed by using TG-DSC with NAU $\cdot \mathrm{H}_{2} \mathrm{O}$ as a reference. The TG-DSC plot of NAU. $\mathrm{H}_{2} \mathrm{O}$ (Fig. 3a) indicates that $\mathrm{NAU} \cdot \mathrm{H}_{2} \mathrm{O}$ dehydrated from 100 to $150{ }^{\circ} \mathrm{C}$ with a corresponding weight loss of $8.96 \%$, which is consistent with the stoichiometric ratio of $1: 1$ for $\mathrm{NAU} \cdot \mathrm{H}_{2} \mathrm{O}$. According to Fig. 3b, no water trace remained after dehydration of NAU $\cdot \mathrm{H}_{2} \mathrm{O}$. For the sample obtained from DMSO (Fig. 3c), the loss of weight and the corresponding endothermic peak below $120^{\circ} \mathrm{C}$ imply that the sample is a DMSO solvate. The weight loss of DMSO solvate $(31 \%)$ can give a NAU-to-DMSO stoichiometric ratio of about 1:1.

High-quality crystal of the DMSO solvate of NAU (NAU.DMSO) was cultivated, and the crystal structure was determined by SCXRD. The detailed crystallographic data are listed in Table 1. The NAU-DMSO crystallizes in the orthorhombic Pbca space group. The 1:1 stoichiometric ratio of NAU to DMSO is consistent with the result of the TG experiment. All the NAU molecules are precisely recognized as Tautomer A. Crystal packing diagrams along three axes are shown in Fig. 4. Figure 4a, c shows that the crystal is stacked along the $c$-axis with a layer structure parallel to $a o b$. The layer (Fig. 4a) is
Table 1 Crystallographic data of DMSO solvate

\begin{tabular}{ll}
\hline & NAU·DMSO \\
\hline Formula & $\mathrm{C}_{8} \mathrm{H}_{14} \mathrm{~N}_{4} \mathrm{O}_{4} \mathrm{~S}$ \\
Crystal system & Orthorhombic \\
Space group & Pbca \\
Temperature $(\mathrm{K})$ & $113(2)$ \\
$a(\AA)$ & $17.526(4)$ \\
$b(\AA)$ & $5.6789(11)$ \\
$c(\AA)$ & $23.439(5)$ \\
$\alpha\left(^{\circ}\right)$ & 90 \\
$\beta\left(^{\circ}\right)$ & 90 \\
$\gamma\left({ }^{\circ}\right)$ & 90 \\
Cell volume $\left(\AA^{3}\right)$ & $2332.9(8)$ \\
Calc density $\left(\mathrm{g} / \mathrm{cm}^{3}\right)$ & 1.494 \\
$Z$ & 8 \\
$\left.R_{\text {int }}\right)$ & 0.0674 \\
$R_{I}(I>2 \sigma(I))$ & 0.0524 \\
$\omega R_{2}$ & 0.1656 \\
$\mathrm{GOF}(\mathrm{S})$ & 0.998 \\
$\mathrm{CCDC}$ & $1,946,769$ \\
\hline
\end{tabular}
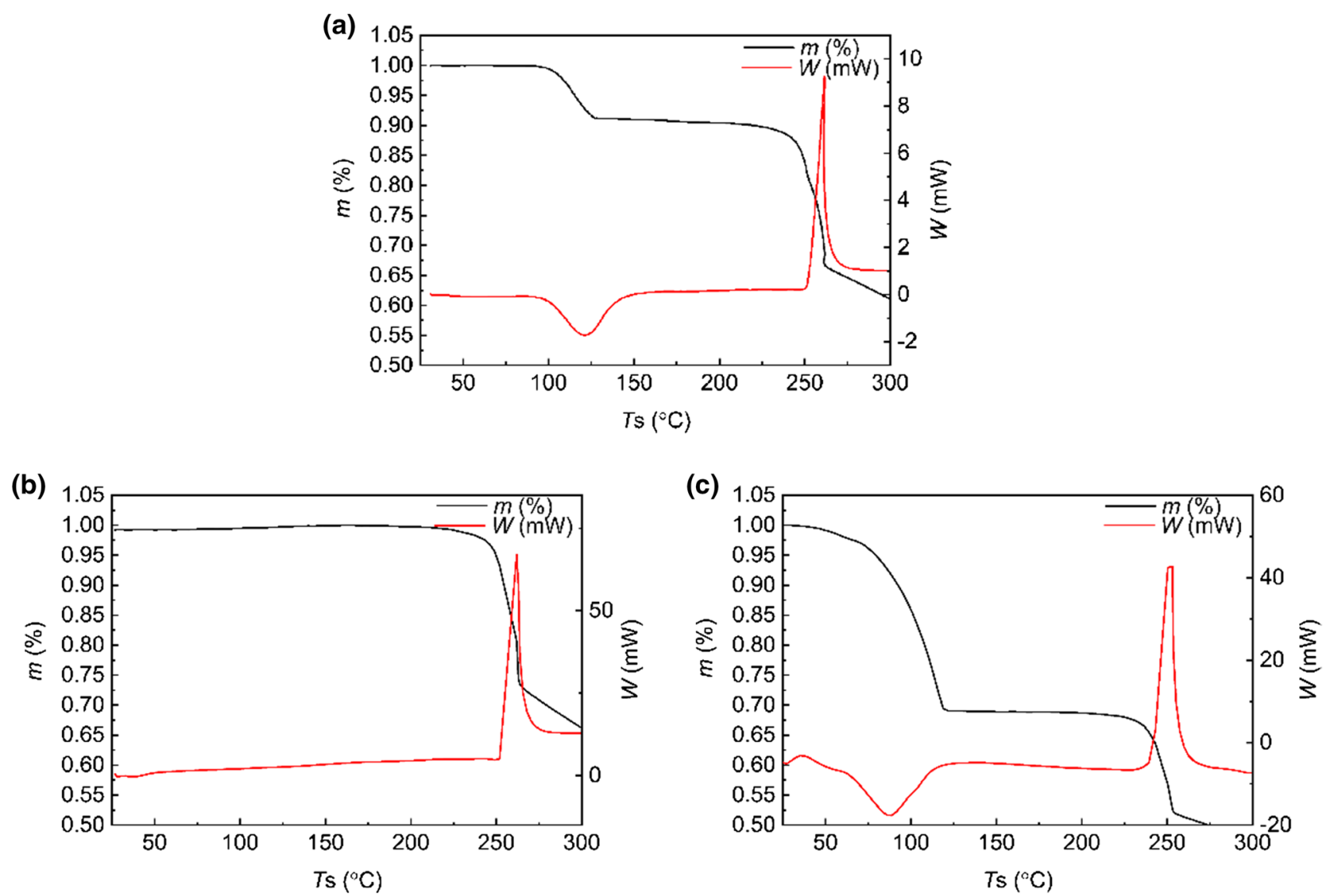

Fig. 3 TG-DSC plots of a NAU $\cdot \mathrm{H}_{2} \mathrm{O}, \mathbf{b}$ NAU, and $\mathbf{c}$ the sample obtained from DMSO 
composed of a packing unit that contains 2 NAU and 2 DMSO molecules. Inside the layer, the packing units form a herringbone motif (Fig. 4b). The herringbone motifs of neighbored layers are interlaced. Figure $4 d$ gives the detailed diagram of the packing unit. Inside the packing unit, the two NAU molecules form a ring complex $R_{2}^{2}(12)$ via two N-H-O (2.420 $\left.\mathrm{A}, 133.10^{\circ}\right)$ hydrogen bonds between the $\mathrm{H}$ atom from the $-\mathrm{NH}_{2}$ of one NAU molecule and the $\mathrm{O}$ atom from $-\mathrm{N}=\mathrm{O}$ of the other NAU molecule. The same $\mathrm{H}$ atom from the $-\mathrm{NH}_{2}$ of NAU also forms an intramolecular $\mathrm{N}-\mathrm{H}-\mathrm{O}\left(1.911 \AA 2,134.61^{\circ}\right)$ hydrogen bond. The two DMSO molecules are connected to the NAU molecules via N-H-O $\left(1.966 \AA\right.$ A $\left.162.88^{\circ}\right)$ hydrogen bonds between the $\mathrm{O}$ atom of DMSO and the $\mathrm{H}$ atom from the $-\mathrm{NH}_{2}$ of NAU. This finding implies that the DMSO molecules contribute to the stabilization of Tautomer A in crystal. The packing units of the herringbone motif in each layer are connected by structure $(\mathbf{e})$ via $\mathrm{C}=\mathrm{O}-\mathrm{C}$ $\left(2.848 \AA, 157.05^{\circ}\right)$. Neighbored layers interact via two $\mathrm{C}-\mathrm{H}-\mathrm{O}\left(2.479 \AA 2136.67^{\circ}\right.$ and $\left.2.569 \AA, 134.48^{\circ}\right)$ bonds in structure (f) between the two $\mathrm{H}$ atoms from $-\mathrm{CH}_{3}$ of DMSO and $\mathrm{O}$ atom from carbonyl adjacent to nitroso in NAU.

\section{Identification of NAU Tautomeric Form in DMSO Solution}

\section{ESP Analysis}

The tautomer state in solution may be influenced by solvent-solute interaction, which is important to possible tautomerization during crystallization. Compared with the solvent role of stabilizing Tautomer A in crystal, the effect of DMSO on the tautomer in a solution is more complex due to the irregular molecular arrangement and complex molecular vibration and movement. To identify NAU tautomer form in solution, ESP of DMSO and two NAU tautomers were analyzed first to find the possible solvent-solute interaction sites [37]. In the ESP maps (Fig. 5), the blue and red indicate negatively and positively charged regions, respectively. The spots on the surface represent the extreme point of potential in the corresponding regions. The most negatively charged region for DMSO (Fig. 5a) locates at the $\mathrm{O}$ atom, while the positive charge disperses on the two methyl groups. The charge distributions for Tautomer A (Fig. 5b) and Tautomer B (Fig. 5c) are similar, where the positive charge focuses on the $\mathrm{H} 2$ in Tautomer A and the $\mathrm{H}_{2}$ ' in Tautomer B. Therefore, the most possible interaction mode in solution should form between the $\mathrm{O}$ atom of DMSO and the $\mathrm{H} 2$ in Tautomer A or the H2' in Tautomer B, which is the same as the DMSO-NAU interaction in crystal.

\section{RDF Analysis}

The possible DMSO-NAU interaction in solution may vary from that provided by ESP analysis because ESP was analyzed in vacuum without conformational variation. Hence, MD simulations with systems containing 1000 DMSO and 8 NAU molecules were performed to discover the DMSO-NAU interaction and the NAU tautomer form in solution more precisely. On the basis of the result of ESP analysis, the $\mathrm{O}$ atom of DMSO and the $\mathrm{N}$ atom of $-\mathrm{NH}_{2}$ from Tautomer $\mathrm{A}$ or the $\mathrm{N}$ atom of $=\mathrm{NH}$ from Tautomer $\mathrm{B}$ were chosen for RDF analysis (Fig. 6), which can be used to evaluate the interaction strength in solution [28]. In RDF results, chemical bonds or hydrogen bonds usually contribute to a sharp peak within $3.5 \AA$, while van der Waals interactions contribute to a peak between 3.5 and $5.0 \AA$ [38]. A sharp peak at $3.03 \AA$ can be observed in Fig. 6a, indicating that the $\mathrm{H} 2$ atom of $-\mathrm{NH}_{2}$ from Tautomer A formed a hydrogen bond with the $\mathrm{O}$ atom of DMSO in the experiment 8A-1000DMSO. Another sharp peak at $3.05 \AA$ can be observed in Fig. $6 \mathrm{~b}$, indicating that the $\mathrm{H}$ atom of $=\mathrm{NH}$ from Tautomer $\mathrm{B}$ also formed a hydrogen bond with the $\mathrm{O}$ atom of DMSO in the experiment 8B-1000DMSO.

\section{Binding Energies of Solute-Solvent Complexes in Solution}

After MD simulations, 13 structures, including monomer and hydrogen bonding solute-solvent complexes, were found in amorphous cells (Fig. S1-S13). Complexes 1-6 and Complexes 7-13 were derived from experiment 8A-1000DMSO and experiment 8B-1000DMSO, respectively.

To evaluate the stabilities of the 13 complexes in solution, the binding energy between NAU and DMSO in each complex was calculated. The information and binding energies of Complexes 1-13 are listed in Table 2. For complexes that contain the same tautomer, complexes with multiple DMSO molecules exhibit higher binding energies and thus are more stable than those that combine one DMSO molecule. This finding indicates that interactions between DMSO and NAU are important to the stability of DMSO-NAU complexes in solution. For complexes with the same DMSO/NAU ratio, all the complexes of Tautomer A show higher binding energies and thus better stability than the corresponding complexes of Tautomer B. According to Table 3, Complexes 2, 3 , and 8 express the highest binding energies and stabilities in solution.

Notably, tautomerization from Tautomer B to Tautomer A was discovered for some complexes of Tautomer B during the optimization calculation, whereas no TS was found from Tautomer B to Tautomer A. The tautomerization occurred for both 1:1 complex (Complex 13) and 2:1 complex (Complexes 8-10). A comparison of those complexes showed that the DMSO-NAU interaction site was critical for the 
(a)

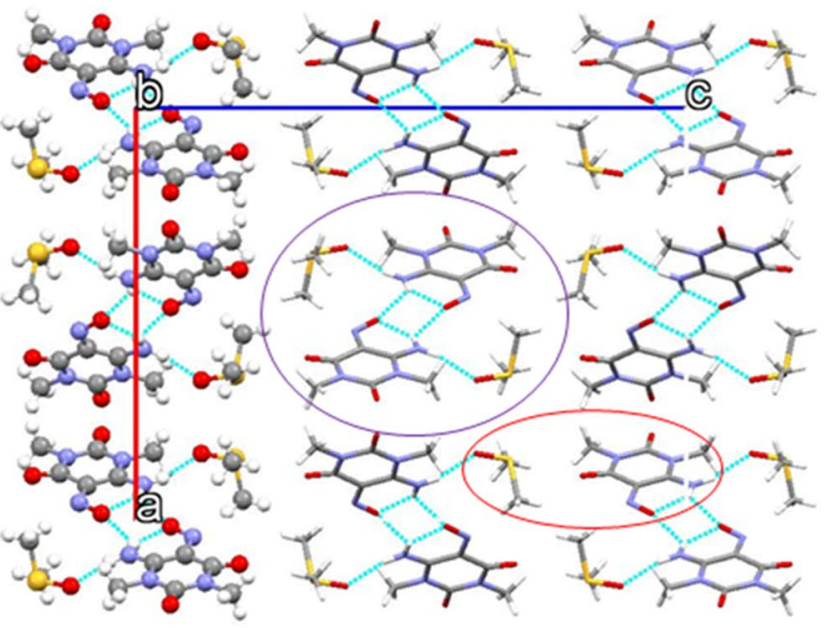

(c)

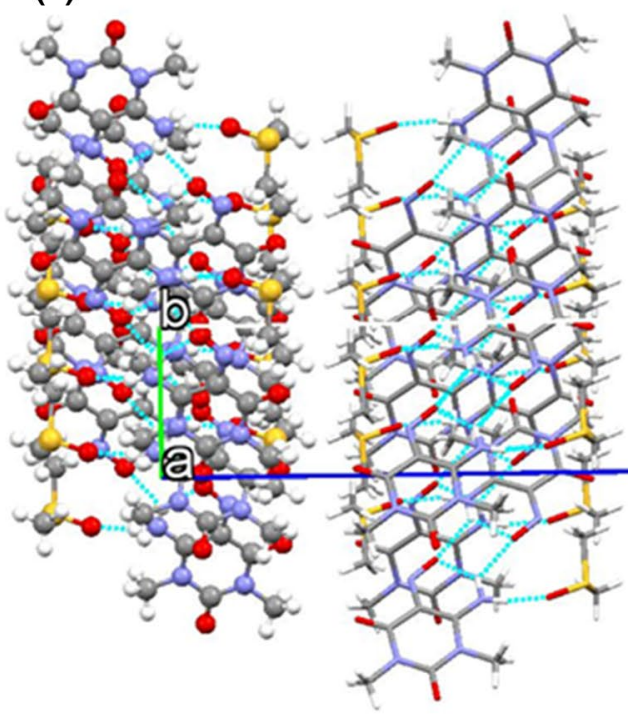

(e)

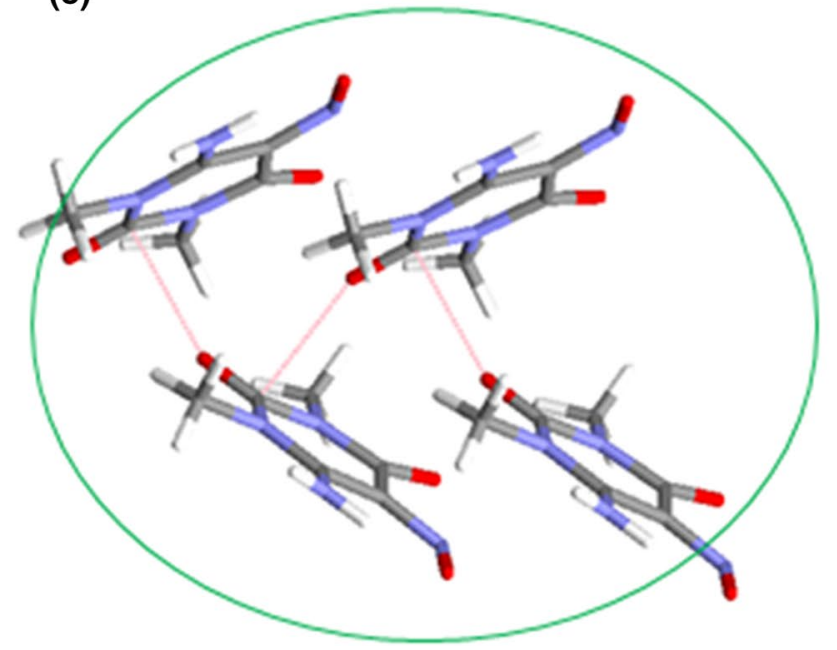

(b)
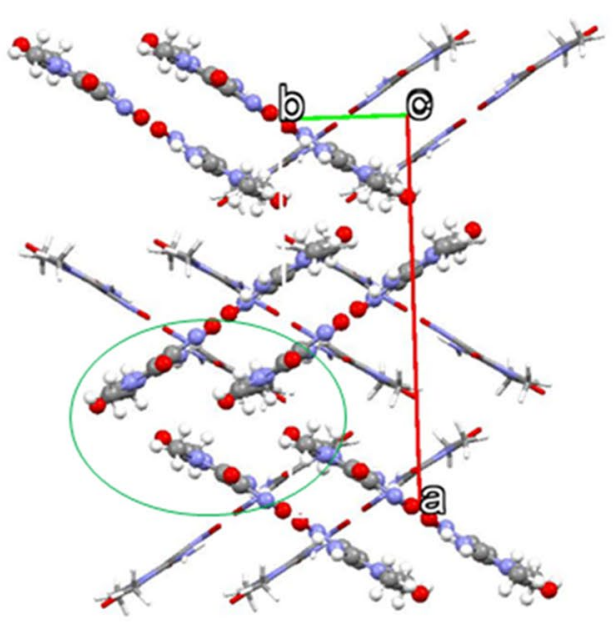

(d)

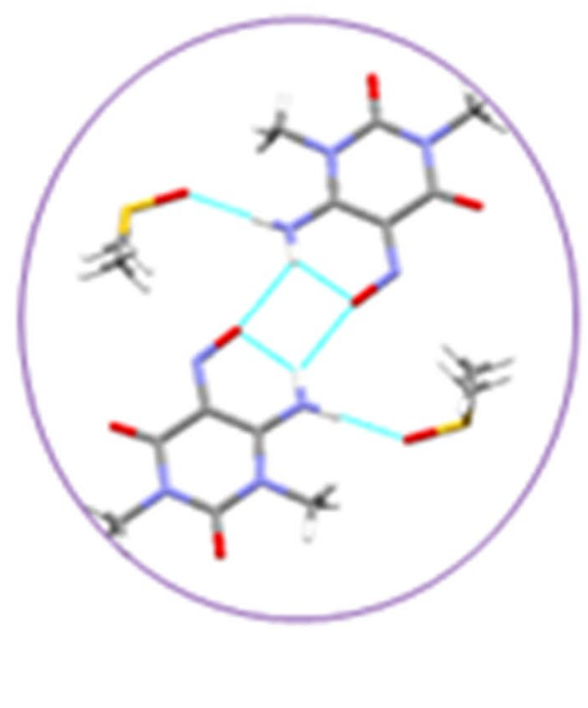

(f)

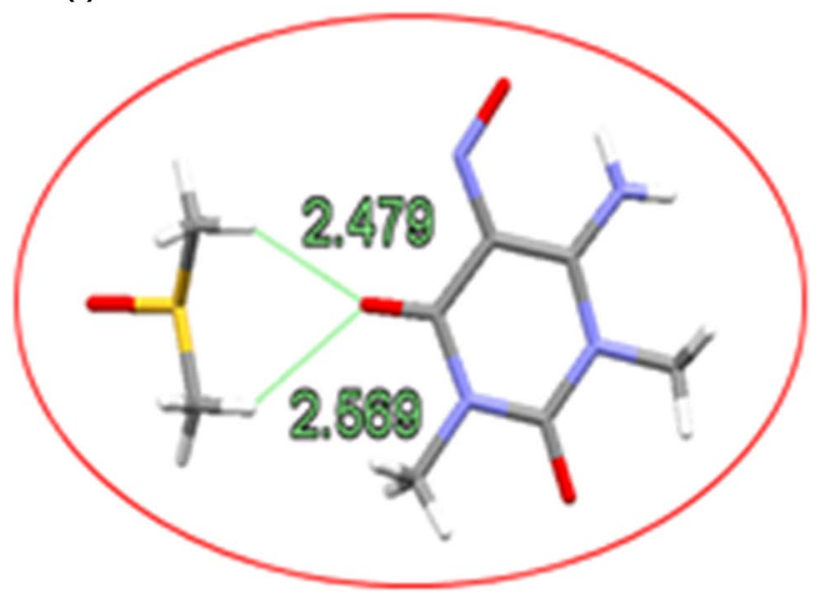


4Fig. 4 Crystal packing diagrams of NAU.DMSO solvate view along: a $b$-axis, $\mathbf{b} c$-axis (DMSO molecules are removed for clarity), and c $a$-axis. Molecules shown in stick-ball model in a-c represent the same layer of molecules. d Diagram of packing unit. e Interaction between NAU in the layer. F Weak interactions between neighbored layers. Molecules in boxes with the same color have the same structure in different diagrams

tautomerization from Tautomer B to Tautomer A. In case the $\mathrm{O}$ atom of DMSO locates between the $\mathrm{H}^{\prime}$ ' and $\mathrm{H} 2^{\prime}$ of Tautomer B in the complex, as illustrated in Fig. 7 (Complex 9 as an example), the $\mathrm{O}$ atom of DMSO (negative charge center of DMSO, Fig. 5a) preferred to move toward the $\mathrm{N}$ atom of NAU (positive charge center, Fig. 5c). Consequently, $\mathrm{H} 1$ of NAU transferred from the $\mathrm{O}$ atom of $-\mathrm{N}-\mathrm{O}-\mathrm{H}$ to the $\mathrm{N}$ atom of $\mathrm{C}=\mathrm{N}-\mathrm{H}$ and experienced tautomerization via attraction from both the $\mathrm{O}$ atom of the DMSO and the $\mathrm{N}$ atom of $\mathrm{C}=\mathrm{N}-\mathrm{H}$ from NAU.

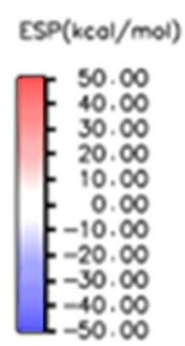

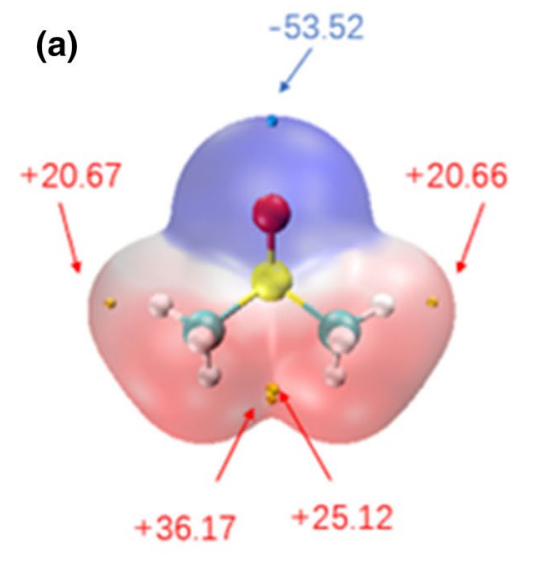

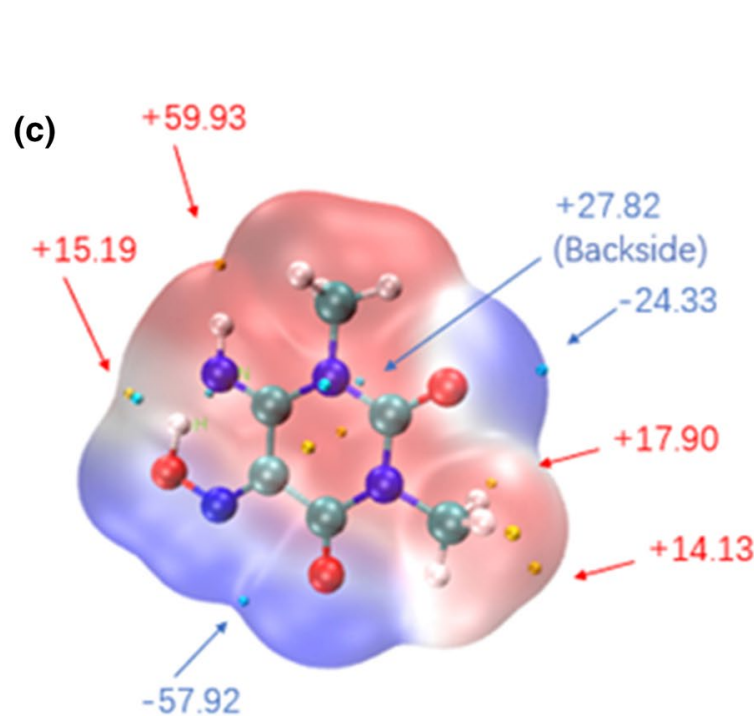

Fig. 5 ESP analysis of a DMSO, b Tautomer A, and $\mathbf{c}$ Tautomer B
Cases were also found in which the DMSO molecule located around $\mathrm{H} 2$ and formed a hydrogen bond with NAU. To further determine the role of this DMSO molecule in possible tautomerization, the energies of monostructure and 1:1 DMSO-tautomer complexes were calculated and the corresponding TS was searched. Vacuum was chosen for simulation experiments to eliminate the effects of all other molecules. Pure tautomers have similar energies; a TS with high energy barrier (Fig. 8a) indicates difficult mutual conversions between the two tautomers. The DMSO-Tautomer B complex exhibits higher energy than the DMSO-Tautomer A complex (Fig. 8b). Moreover, the location of the TS of these complexes is close to that of the DMSO-Tautomer B complex, which gives a low barrier for the conversion from Tautomer B to Tautomer A. This result implies that interactions between DMSO and NAU promote the transformation from Tautomer $\mathrm{B}$ to Tautomer A in both thermodynamics and kinetics.

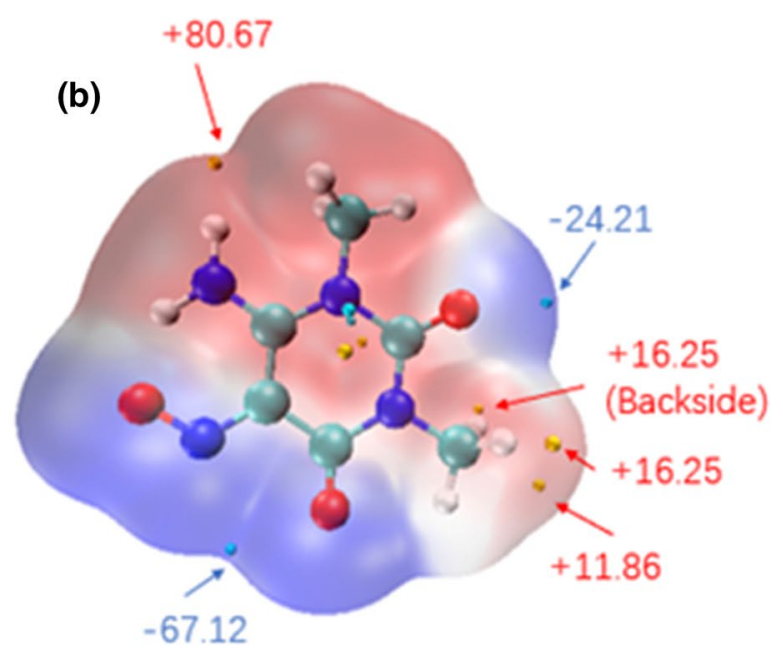

$-67.12$ 

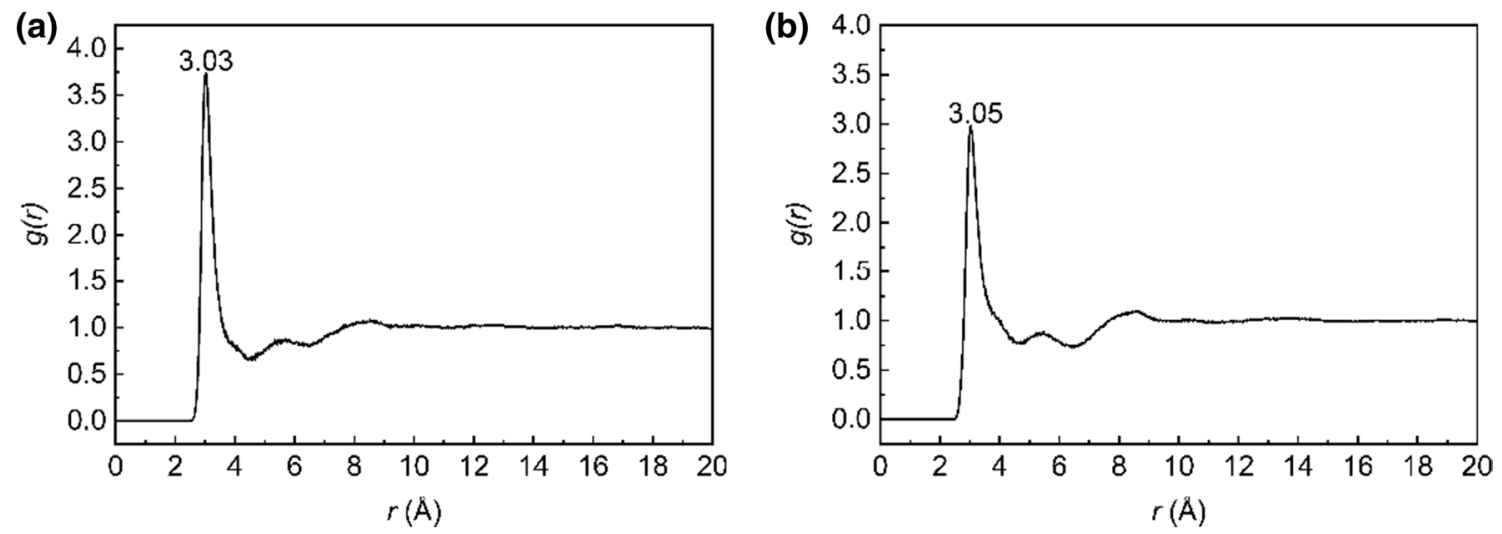

Fig. 6 RDF $(g(r))$ in the system containing 1000 DMSO and 8 NAU molecules (a Tautomer A and b Tautomer B)

Table 2 Binding energies of possible dominant complexes

\begin{tabular}{lllll}
\hline Optimized complex & $\begin{array}{l}\text { Initial tautomer } \\
\text { form }\end{array}$ & Tautomer form & $\begin{array}{l}\text { DMSO/NAU } \\
\text { ratio }\end{array}$ & $\begin{array}{l}\text { Binding energy } \\
(\mathrm{kJ} / \mathrm{mol})\end{array}$ \\
\hline Complex 1 & A & A & 0 & 0 \\
Complex 2 & A & A & 2 & -54.92 \\
Complex 3 & A & A & 2 & -53.27 \\
Complex 4 & A & A & 1 & -31.04 \\
Complex 5 & A & A & 1 & -30.75 \\
Complex 6 & A & A & 1 & -29.59 \\
Complex 7 & B & B & 0 & 0 \\
Complex 8 & B & A & 2 & -55.71 \\
Complex 9 & B & A & 1 & -28.53 \\
Complex 10 & B & A & 1 & -30.13 \\
Complex 11 & B & B & 1 & -19.60 \\
Complex 12 & B & B & 1 & -14.15 \\
Complex 13 & B & A & 1 & -28.32 \\
\hline
\end{tabular}

Table 3 Experimental and predicted chemical shifts for $\mathrm{H}$ in Complexes 1-13

\begin{tabular}{|c|c|c|c|c|c|c|c|c|}
\hline \multirow[t]{2}{*}{ Complexes } & \multicolumn{2}{|l|}{$\mathrm{H} 1\left(^{\prime}\right)$} & \multicolumn{2}{|l|}{$\mathrm{H} 2\left(^{\prime}\right)$} & \multicolumn{2}{|c|}{$\mathrm{H} 3\left(^{\prime}\right) \& \mathrm{H} 4\left(^{\prime}\right)$} & \multicolumn{2}{|l|}{$Q$} \\
\hline & B97D & B3LYP & B97D & B3LYP & B97D & B3LYP & B97D & B3LYP \\
\hline Complex 1 & 13.39 & 13.10 & 4.99 & 5.16 & 3.44 & 3.45 & 17.026 & 15.524 \\
\hline Complex 2 & 12.84 & 12.63 & 9.21 & 9.57 & 3.43 & 3.46 & 0.210 & 0.605 \\
\hline Complex 3 & 12.79 & 12.69 & 9.95 & 10.19 & 3.43 & 3.47 & 0.968 & 1.590 \\
\hline Complex 4 & 13.03 & 12.74 & 10.23 & 10.53 & 3.44 & 3.49 & 1.561 & 2.496 \\
\hline Complex 5 & 13.09 & 12.79 & 10.19 & 10.44 & 3.45 & 3.49 & 1.474 & 2.224 \\
\hline Complex 6 & 12.85 & 12.58 & 10.42 & 10.73 & 3.44 & 3.47 & 2.013 & 3.169 \\
\hline Complex 7 & 20.43 & 20.57 & 7.40 & 7.54 & 3.40 & 3.40 & 58.666 & 60.351 \\
\hline Complex 8 & 12.77 & 12.52 & 10.49 & 10.77 & 3.41 & 3.46 & 2.188 & 3.297 \\
\hline Complex 9 & 12.89 & 12.60 & 10.30 & 10.63 & 3.42 & 3.49 & 1.675 & 2.882 \\
\hline Complex 10 & 13.07 & 12.76 & 10.19 & 10.44 & 3.46 & 3.51 & 1.507 & 2.292 \\
\hline Complex 11 & 20.37 & 20.45 & 7.45 & 7.56 & 3.34 & 3.34 & 57.584 & 58.374 \\
\hline Complex 12 & 20.57 & 20.71 & 7.50 & 7.61 & 3.34 & 3.36 & 60.436 & 62.212 \\
\hline Complex 13 & 12.91 & 12.59 & 10.37 & 10.64 & 3.45 & 3.52 & 1.902 & 2.988 \\
\hline Experimental & 12.96 & & 9.07 & & 3.26 & & & \\
\hline
\end{tabular}


Fig. 7 Tautomerization diagrams of Complex 9

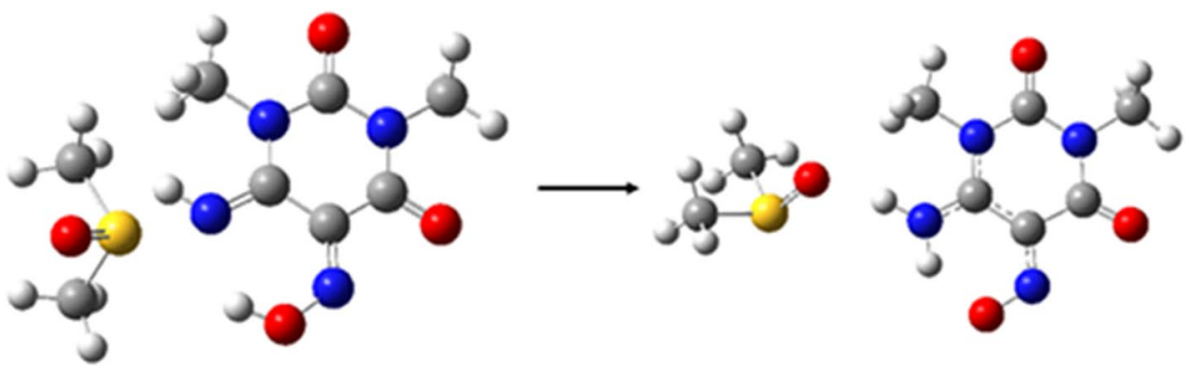

(a)

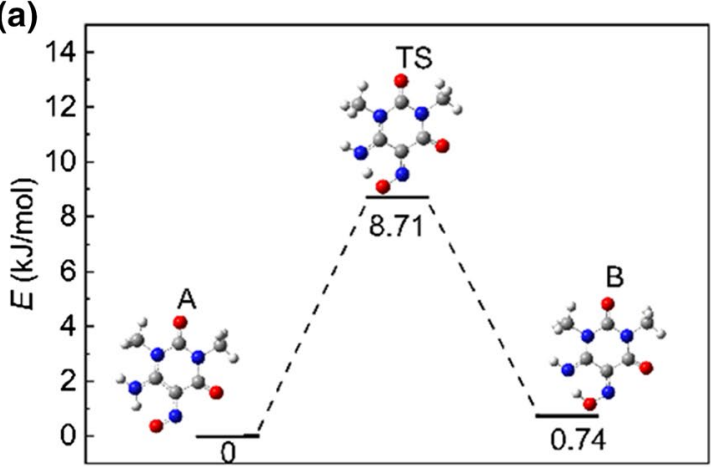

(b)

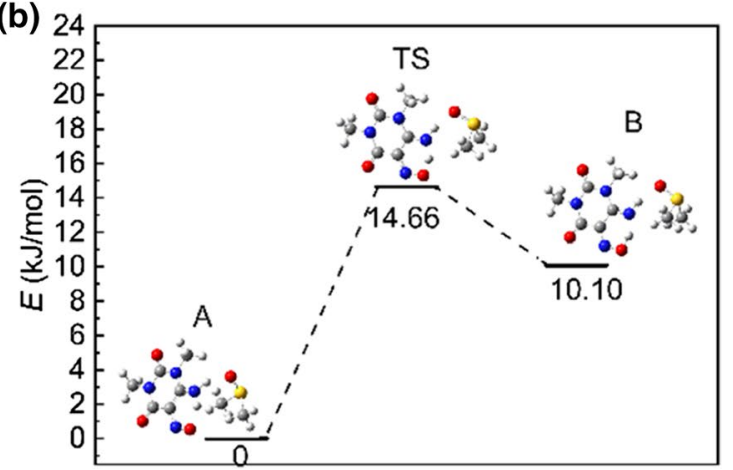

Fig. 8 Potential energy profiles in vacuum for Tautomer A, Tautomer B, and TS of a monostructure and $\mathbf{b}$ hydrogen bonding complex

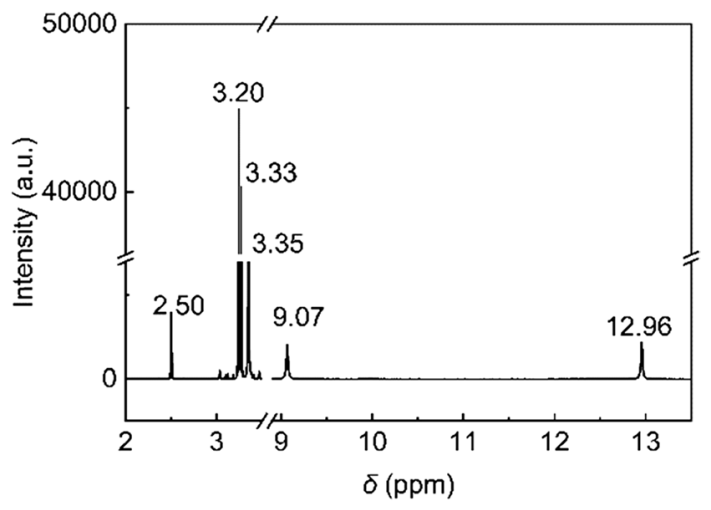

Fig. $9{ }^{1} \mathrm{H}$ NMR of NAU in DMSO- $\mathrm{d}_{6}$ solution

\section{${ }^{1} \mathrm{H}$ NMR Calculation and Verification}

${ }^{1} \mathrm{H}$ NMR has been widely used in many tautomer systems to determine the tautomer states, for example, Schiff base $[4,35]$, porphyrin [7], azo dyes [39], and other substances [40-43]. We also measured the ${ }^{1} \mathrm{H}$ NMR spectra of the DMSO solution of NAU (Fig. 9) to determine the tautomeric form in solution. The peaks at 2.50 and 3.35 could be associated with impurities of DMSO without deuterium and water, respectively. The peaks at 3.20 and 3.33 belong to the two methyls in NAU. However, the peaks at 9.07 and 12.96 are difficult to assign due to the similar positions and environment of $\mathrm{H} 1\left(^{\prime}\right)$ and $\mathrm{H} 2\left(^{\prime}\right)$ in the two tautomer forms.
The ${ }^{1} \mathrm{H}$ NMR spectra of possible complexes (Complexes 1-13) in the DMSO solution were then predicted at B97D/6$31+\mathrm{G}(\mathrm{d}, \mathrm{p})$ and B3LYP/6-311+G(d,p) levels, whose accuracy had been proven [30.35]. The experimental and predicted chemical shifts are shown in Table 3 . The residual sum of square $(Q)$ of each complex was calculated by the following formula:

$Q=\sum_{i=1}^{4}\left(y_{i}-\hat{y}_{\mathrm{i}}\right)^{2} \times n_{i}$

where $y_{\mathrm{i}}$ is the experimental chemical shift of $\mathrm{H}_{i}(i=1-4) ; \hat{y}_{\mathrm{i}}$ is the predicted chemical shift of $\mathrm{H}_{i}$; and $n_{i}$ is the number of $\mathrm{H}$ in each functional group. The chemical shifts of $6 \mathrm{H}$ atoms from the two methyls are close enough to be calculated as one kind of hydrogen.

According to Table 3, the residual sums of square of Complexes 2 and 3 are small enough to be acceptable at both B97D/6-31 + G(d,p) and B3LYP/6-311+G(d,p) levels. This finding demonstrates that the peaks at 9.07 and 12.96 in experimental ${ }^{1} \mathrm{H}$ NMR spectra could be assigned to Tautomer A-containing complexes. The difference between experimental and predicted chemical shifts for $\mathrm{H}$ may be attributed to the van der Waals interactions being ignored for simplicity. By comparing the discussion results of complex stability and ${ }^{1} \mathrm{H}$ NMR spectra, one can conclude that Tautomer A would dominate in the DMSO solution via the interaction with DMSO molecules. 
Fig. 10 Diagrams of dominating Complexes 2 and 3

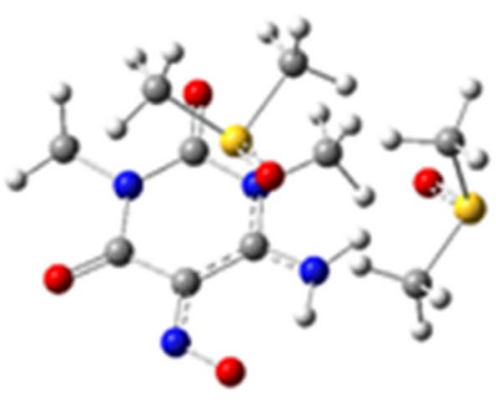

(Complex 2)

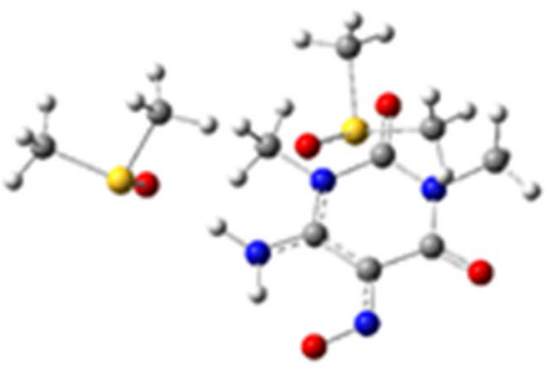

(Complex 3)

\section{Tautomeric Form Preservation During Solvate Crystallization}

The optimization results for the dominating Complexes 2 and 3 in solution are illustrated in Fig. 10. The findings indicate that only one DMSO molecule can form a stable hydrogen bond with Tautomer A at H2, which helps stabilize Tautomer A in solution. In NAU.DMSO crystal, Tautomer $\mathrm{A}$ is preserved, and DMSO and Tautomer A have hydrogen bonding with the same type of interaction. Although other DMSO molecules in the first solvent layer have weak van der Waals force with Tautomer A in solution, they have no chance to enter the crystal. A comparison of the interaction between DMSO and Tautomer A in solution and in crystal indicates that such hydrogen bonding from the $\mathrm{O}$ atom of DMSO and $\mathrm{H} 2$ of Tautomer A plays an important role in preserving Tautomer A during solvate crystallization.

\section{Conclusions}

A solvate with NAU/DMSO ratio of 1:1 was discovered, and its crystal structure was determined. Only Tautomer A exists in NAU-DMSO solvate crystal. The packing unit of the crystal is composed of 2 Tautomer A connecting via a $R_{2}^{2}(12)$ motif and 2 DMSO molecules hydrogen bonding to Tautomer A via N-H-O (1.966 ̊, 162.88 $)$. Tautomer A also exhibits an intramolecular N-H-O (1.911 ̊, 134.61 $\left.{ }^{\circ}\right)$ hydrogen bond. The crystal is stacked along the $c$-axis with layers that are parallel to the $a o b$ face. Inside the layer, the packing units form a herringbone motif. The herringbone motifs in the neighbored layers are not parallel but interlaced. ESP analysis shows that the negative charge of DMSO focuses on the $\mathrm{O}$ atom. The positive charge center locates near H2(') for both Tautomer A and Tautomer B, with Tautomer A having a higher positive charge density. RDF analysis indicates a strong hydrogen bond interaction within the first solvent layer of NAU. MD simulations of the systems that contain 1000 DMSO and 8 NAU molecules were conducted, and 13 complexes in solution were obtained, with Complexes 2, 3, and 8 showing the highest binding energies and stability. Stable Tautomer B-containing complexes have higher energy than corresponding complexes of Tautomer A. Two effects of DMSO were found in this case. Transition from Tautomer B to Tautomer A was discovered during structure optimization when the $\mathrm{O}$ atom of DMSO locates between the $\mathrm{H}^{\prime}$ ' and $\mathrm{H} 2$ ' atoms of Tautomer $\mathrm{B}$ in complexes. The TS search result implies that the hydrogen bond between the $\mathrm{O}$ atom of DMSO and the $\mathrm{H} 2^{\prime}$ atom of Tautomer $\mathrm{B}$ could promote the transition from Tautomer B to Tautomer A. A comparison of predicted and experimental ${ }^{1} \mathrm{H}$ NMR spectra verified that Tautomer A-containing complexes (Complexes 2 and 3) dominate in the DMSO solution. The hydrogen bonding between DMSO and NAU is similar in solution and in NAU.DMSO solvate crystal, which helps preserve the form of Tautomer A during solvate crystallization. A variety of solid-state NMR spectra may be useful for determining tautomeric form in solid states. Thus, further research and efforts can be expected and will be crucial.

Acknowledgements The authors thank the financial support from the National Natural Science Foundation of China (No. 21776204).

Accession Codes CCDC 1946769 contains the supplementary crystallographic data for this paper. These data can be obtained free of charge via www.ccdc.cam.ac.uk/data_request/cif, or by emailing data_ request@ccdc.cam.ac.uk, or by contacting The Cambridge Crystallographic Data Centre, 12 Union Road, Cambridge CB2 1EZ, UK; fax: +44 1223336033 .

Open Access This article is licensed under a Creative Commons Attribution 4.0 International License, which permits use, sharing, adaptation, distribution and reproduction in any medium or format, as long as you give appropriate credit to the original author(s) and the source, provide a link to the Creative Commons licence, and indicate if changes were made. The images or other third party material in this article are included in the article's Creative Commons licence, unless indicated otherwise in a credit line to the material. If material is not included in the article's Creative Commons licence and your intended use is not permitted by statutory regulation or exceeds the permitted use, you will need to obtain permission directly from the copyright holder. To view a copy of this licence, visit http://creativecommons.org/licenses/by/4.0/. 


\section{References}

1. Wang T, Stevens JS, Vetter T et al (2018) Salts, cocrystals, and ionic cocrystals of a "simple" tautomeric compound. Cryst Growth Des 18(11):6973-6983

2. Cruz-Cabeza AJ, Groom CR (2011) Identification, classification and relative stability of tautomers in the Cambridge structural database. CrystEngComm 13(1):93-98

3. Porter WR (2010) Warfarin: history, tautomerism and activity. J Comput Aided Mol Des 24(6-7):553-573

4. Arun V, Mathew S, Robinson PP et al (2010) The tautomerism, solvatochromism and non-linear optical properties of fluorescent 3-hydroxyquinoxaline-2-carboxalidine-4-aminoantipyrine. Dye Pigment 87(2):149-157

5. Gao J, Hu YJ, Li SX et al (2013) Tautomeric equilibrium of creatinine and creatininium cation in aqueous solutions explored by Raman spectroscopy and density functional theory calculations. Chem Phys 410:81-89

6. Zhang LS, Shen SN, Gao YL et al (2019) Tautomerism and bioactivities of curcumenol, a common sesquiterpenoid widely existing in edible plants. Food Funct 10(3):1288-1294

7. Furuta H, Ishizuka T, Osuka A et al (2001) NH tautomerism of N-confused porphyrin. J Am Chem Soc 123(25):6207-6208

8. Kyrychenko A, Waluk J (2006) Excited-state proton transfer through water bridges and structure of hydrogen-bonded complexes in 1H-pyrrolo[3, 2-h]quinoline: adiabatic timedependent density functional theory study. J Phys Chem A 110(43):11958-11967

9. Kyrychenko A, Stepanenko Y, Waluk J (2000) Molecular dynamics and DFT studies of intermolecular hydrogen bonds between bifunctional heteroazaaromatic molecules and hydroxylic solvents. J Phys Chem A 104(42):9542-9555

10. Zhang C, Xie L, Ding YQ et al (2016) Real-space evidence of rare guanine tautomer induced by water. ACS Nano 10(3):3776-3782

11. Kyrychenko A, Herbich J, Izydorzak M et al (1999) Role of ground state structure in photoinduced tautomerization in bifunctional proton donor-acceptor molecules: $1 \mathrm{H}$-pyrrolo[3, 2-h]quinoline and related compounds. J Am Chem Soc 121(48):11179-11188

12. Mente S, Maroncelli M (1998) Solvation and the excited-state tautomerization of 7-azaindole and 1-azacarbazole: computer simulations in water and alcohol solvents. J Phys Chem A 102(22):3860-3876

13. Balta B, Aviyente V (2003) Solvent effects on Glycine: I. A supermolecule modeling of tautomerization via intramolecular proton transfer. J Comput Chem 24(14):1789-1802

14. Bakker JM, Sinha RK, Besson T et al (2008) Tautomerism of uracil probed via infrared spectroscopy of singly hydrated protonated uracil. J Phys Chem A 112(48):12393-12400

15. Delaney SP, Witko EM, Smith TM et al (2012) Investigating tautomeric polymorphism in crystalline anthranilic acid using terahertz spectroscopy and solid-state density functional theory. J Phys Chem A 116(30):8051-8057

16. Ogawa K, Fujiwara T, Harada J (2000) A crystallographic study on the thermochromism of salicylideneanilines. Mol Cryst Liq Cryst Sci Technol Sect A Mol Cryst Liq Cryst 344(1):169-178

17. Hadjoudis E, Mavridis IM (2004) Photochromism and thermochromism of Schiff bases in the solid state: structural aspects. Chem Soc Rev 33:579-588

18. Wang L, Luo M, Li JH et al (2015) Sweet theophylline cocrystal with two tautomers of acesulfame. Cryst Growth Des 15(6):2574-2578
19. Joseph A, Rodrigues Alves JS, Bernardes CES et al (2019) Tautomer selection through solvate formation: the case of 5-hydroxynicotinic acid. CrystEngComm 21(13):2220-2233

20. Hauptmann R, Petrosyan A, Fennel F et al (2019) Pyrimidopteridine N-oxide organic photoredox catalysts: characterization, application and non-covalent interaction in solid state. Chem Eur J 25(17):4325-4329

21. Shirsagar UVK, Bhave VG (1997) Synthesis of 1, 3-dimethyl4-amino-5-nitroso-2, 6-pyrimidinedione and its derivatives. J Indian Chem Soc 74(8):649-651

22. Yoneda F, Nagamatsu T, Ogiwara K et al (1978) Synthesis and properties of 1, 3-dimethyl-6-azalumazines (Isofervenulins). Chem Pharm Bull 26(2):367-373

23. Sako M, Ohara S, Hirota K et al (1991) Mechanistic aspects of the oxidation of 1,3-disubstituted 6-amino-5-nitrosouracils with lead tetraacetate: the formation of pyrimido[5, 4-g]pteridinetetrone 10-oxides. J Org Chem 56(22):6302-6306

24. Zhang G, Dang L, Wei H (2018) Investigations on dehydration process of trisodium phosphate dodecahydrate. Chem Ind Eng 35(4):46-51 (in Chinese)

25. Sheldrick GM (2008) A short history of SHELX. Acta Cryst Sect A 64(1):112-122. https://doi.org/10.1107/s010876730 7043930

26. Sheldrick GM (2015) Crystal structure refinement with SHELXL. Acta Crystallogr C 71(1):3-8. https://doi. org/10.1107/s2053229614024218

27. Rukmani SJ, Kupgan G, Anstine DM et al (2019) A molecular dynamics study of water-soluble polymers: analysis of force fields from atomistic simulations. Mol Simul 45(4-5):310-321. https://doi.org/10.1080/08927022.2018.1531401

28. Quan YF, Yang Y, Xu SJ et al (2019) Insight into the role of piperazine in the thermodynamics and nucleation kinetics of the triethylenediamine-methyl tertiary butyl ether system. CrystEngComm 21(6):948-956. https://doi.org/10.1039/c8ce01179f

29. Desiraju GR, Steiner T (2001) The weak hydrogen bond. In: structural chemistry and biology. Oxford University Press, Oxford. ISBN:978-0-19-850970-7. https://doi.org/10.1093/ acprof:oso/9780198509707.001.0001

30. Du W, Cruz-Cabeza AJ, Woutersen S et al (2015) Can the study of self-assembly in solution lead to a good model for the nucleation pathway? The case of tolfenamic acid. Chem Sci 6(6):3515-3524. https://doi.org/10.1039/c5sc00522a

31. Alvarado-González M, Flores-Holguín N, Gallo M et al (2010) TD-DFT/IEFPCM determination of the absorption and emission spectra of DABCYL. J Mol Struct: THEOCHEM 945(13):101-103. https://doi.org/10.1016/j.theochem.2010.01.014

32. Suleimanov YV, Green WH (2015) Automated discovery of elementary chemical reaction steps using freezing string and Berny optimization methods. J Chem Theory Comput 11(9):42484259. https://doi.org/10.1021/acs.jctc.5b00407

33. Padrela L, Zeglinski J, Ryan K (2019) Unraveling the link between solvent-mediated proton transfer and the salt formation of saccharin and sulfamethazine. Cryst Growth Des 19(2):613619. https://doi.org/10.1021/acs.cgd.8b01015

34. Cheeseman JR, Trucks GW, Keith TA et al (1996) A comparison of models for calculating nuclear magnetic resonance shielding tensors. J Chem Phys 104(14):5497-5509. https://doi. org/10.1063/1.471789

35. Kaur M, Kaur H, Kapila A et al (2019) Tautomerism, spectroscopic and computational analysis of Schiff base and its diphenyltin (IV) complex. J Mol Struct 1185:57-68. https:// doi.org/10.1016/j.molstruc.2019.02.077

36. Fathima RB, Prasana JC, Muthu S et al (2019) Molecular docking studies, charge transfer excitation and wave function analyses (ESP, ELF, LOL) on valacyclovir: a potential antiviral drug. 
Comput Biol Chem 78:9-17. https://doi.org/10.1016/j.compb iolchem.2018.11.014

37. Pei TZ, Zhou LN, Zhang Q et al (2019) Studies on structure, NLO properties of a new organic NLO crystal: guanidinium 3, 5-dihydroxybenzoate. J Mater Sci: Mater Electron 30(3):29943003. https://doi.org/10.1007/s10854-018-00578-1

38. Liu SY, MacAringue EGJ, Li XN et al (2017) Organic solvent effects on solid-liquid phase equilibrium of d-mannitol and aqueous binary solvents: an experimental and computational study. J Mol Liq 238:411-422. https://doi.org/10.1016/j.molli q.2017.04.127

39. Ghanadzadeh Gilani A, Taghvaei V, Moradi Rufchahi E et al (2019) Tautomerism, solvatochromism, preferential solvation, and density functional study of some heteroarylazo dyes. J Mol Liq 273:392-407. https://doi.org/10.1016/j.molliq.2018.10.054

40. Nigro MJ, Iribarren AM, Laurella SL et al (2018) Keto-enol tautomerism in nucleobase-substituted aldols. ChemistrySelect 3(46):13091-13097. https://doi.org/10.1002/slct.201802538

41. Cai K, Yan QF, Zhao DH (2012) Large hydroazaacene diimides: synthesis, tautomerism, halochromism, and redox-switchable NIR optics. Chem Sci 3(11):3175. https://doi.org/10.1039/c2sc2 $1142 \mathrm{~d}$

42. Su F, Sun ZQ, Su WK et al (2018) NMR investigation and theoretical calculations on the tautomerism of benzimidazole compounds. J Mol Struct 1173:690-696. https://doi. org/10.1016/j.molstruc.2018.07.038

43. Shi KM, Pedersen CM, Guo ZH et al (2018) NMR studies of the tautomer distributions of d-fructose in lower alcohols/DMSOd6. J Mol Liq 271:926-932. https://doi.org/10.1016/j.molli q.2018.09.067

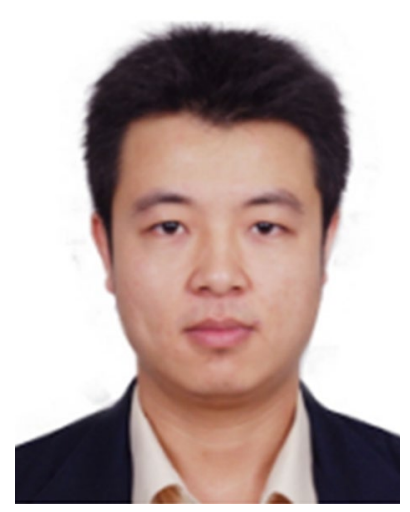

Chuang Xie obtained his bachelor degree and Ph.D. from Tianjin University, China, in 2002 and 2007 , respectively. He is now an associate research fellow at the School of Chemical Engineering and Technology, Tianjin University, China. His research areas include industrial crystallization and partical process, resolution of chiral compounds by crystallization, and research and development of nanomaterials. 